\title{
Fitness of Hybrids between Gossypium barbadense and Upland Cotton and Resistance to Pectinophora gossypiella and Alabama argillacea
}

\author{
Lucia Vieira Hoffmann ${ }^{1}$, Paulo Augusto Vianna Barroso ${ }^{1}$, Jair Moisés de Sousa ${ }^{2}$ and Flora Ismail Tibazarwa ${ }^{3}$ \\ 1. Embrapa, Santo Anthonio de Goias 75375-000, Brazil \\ 2. Federal University of Campina Grande, Patos Campus, University Avenue, Paraíba 58700-970, Brazil \\ 3. Department of Botany, University of Dar es Salaam, Dar Es Salaam 35060, Tanzania
}

Received: May 11, 2013 / Accepted: June 14, 2013 / Published: August 30, 2013.

\begin{abstract}
Measuring fitness is essential for understanding the potential impacts of hybridisation between transgenic crops and their wild relatives. Transgenic Cry1Ac cotton Gossypium hirsutum and G. barbadense hybridise, the latter being valued as backyard cotton and an important genetic resource. G. barbadense was outcrossed to G. hirsutum containing the gene Cry1Ac and the isoline and the offspring evaluated for fitness as a measure of resistance to common pests and other growth parameters. Resistance to Pectinophora gossypiella and Alabama argillacea were greater in transgenic plants. Number of seeds per plant was higher in the $\mathrm{F}_{1}$ hybrids and G. hirsutum, $\mathrm{F}_{2}$ populations were intermediary; G. barbadense produced the least seeds per plant during the period of analysis. Anthesis of the first flower and opening of the first boll occurred earlier for $G$. hirsutum and $\mathrm{F}_{1}$ hybrids than $\mathrm{F}_{2}$; latest for $G$. barbadense. The observed performance of resistance to the worms in the hybrids suggests that among $F_{1}$ and $F_{2}$ populations transgenic hybrids may exhibit a competitive advantage over non-transgenic plants as a result of gene flow.
\end{abstract}

Key words: Biosafety, pink bollworm, cotton leaf worm, gene flow.

\section{Introduction}

Local varieties and wild relatives of crops are valued genetic resources. When wild relatives belong to the primary gene pool of a cultivated species, gene flow and hybridization between the two can potentially occur [1]. There are two main mechanisms to demonstrate that gene flow occurs. The first is to search for morphological characteristics or molecular markers typical of the donor genotype among the progenies of the putative receptor genotypes [2], and the second is to find naturally occurring hybrids.

Hybrids have demonstrated the potential for greater adaptive capacity than their parents competing with them and/or extinguishing them as seen in Raphanus

Corresponding author: Lucia Vieira Hoffmann, Ph.D., research fields: molecular biology, plant genetics and plant microbe interaction. E-mail: lucia.hoffmann@embrapa.br. species [3]. It has been shown in maize that hybrids with or without transgenic backgrounds possess higher vigor than their parents [4]. Measuring the adaptability of interspecific hybrids under controlled conditions is important as it allows one to predict the behaviour of the hybrids if they are to occur in the natural environment.

The cotton species Gossypium barbadense is cultivated in a lesser extent than the upland cotton $G$. hirsutum but is frequently found as backyard cotton. It is not widespread in the natural environment, but is locally valued due to its medicinal value and other uses $[5,6]$.

Although gene flow could not be detected between cotton populations in northeast Brazil using molecular markers [2], natural hybrids between G. hirsutum and G. barbadense may occur since they are sexually 
compatible, albeit not at high frequencies. In a survey of 187 genotypes of G. hirsutum race Marie-Galante, only a single plant was determined a hybrid with $G$. barbadense, suggesting that gene flow occurs [7]. One explanation of the small number of hybrids may be the existence of pollen competition [8]. Non-transgenic $G$. hirsutum and $G$. barbadense have been shown to hybridize under controlled and natural conditions [9], but the fitness of the resulting hybrids is yet to be determined.

Estimating adaptability of crossing outcomes to the environment is best established by selecting characteristics linked to reproduction and vegetative growth, as these may reveal the competitive and reproductive potential of the more adaptive individuals [10].

In this study, a number of reproductive and morphological characters were used to represent competitive advantage of hybrids of $G$. barbadense and transgenic G. hirsutum in light of exposure to two pests, the pink bollworm and the cotton leaf worm. Transgenic Gossypium hirsutum carrying the transgenic Bt trait was first released for commercial production in Brazil in 2005. The characters assessed included plant height, precocity of flowering and boll maturation. Selection of characters was based on experimental ease of measurement and performance in adverse environmental conditions.

\section{Materials and Methods}

Seven genotypes were evaluated:

(1) DP 404 BG: herbaceous cotton plant (G. hirsutum) genetically modified with the Cry1Ac gene whose expression confers resistance to some caterpillars that attack the cotton plant [11];

(2) DP 4049: the non-genetically modified isoline of DP $404 \mathrm{BG}$;

(3) MT 0541: a G. barbadense accession with brown fiber, similar in all other characteristics with specimens of the species maintained as dooryard cotton almost all over the country;
(4) $F_{1}$ Bt: obtained by the outcrossing of DP 404 BG (ô parent) with MT 0541 ( 9 parent);

(5) $F_{1}$ ISOL: obtained by outcrossing of DP 4049 (ठ̊ parent) with MT 0541 (ㅇ parent);

(6) $\mathrm{F}_{2} \mathrm{Bt}$ : obtained by selfing $\mathrm{F}_{1} \mathrm{Bt}$ and selecting the transgenic plants by the expression of the protein, as described above by the SeedChek Bt1Ac Strip Test;

(7) $F_{2}$ ISOL: obtained by the self-crossing of $F_{1}$ ISOL, as seen in Table 1.

The experiment was set in the municipality of Itatuba, in Paraíba state, Brazil $\left(7^{\circ} 23^{\prime} 02,8^{\prime \prime} \mathrm{S}\right.$; $35^{\circ} 32^{\prime} 38,7^{\prime \prime} \mathrm{O}$ ), where the climate is tropical, with an average annual precipitation of $431.8 \mathrm{~mm}$. Seeds were sown on September 11, 2007, and the plants were harvested on March 20, 2008. The experiment had a completely randomized design. The number of replicates varied according to genotype: 20 for each of the parental genotypes (DP 404 BG, DP 4049 and MT 0541); 34 for each $F_{1}$ generation ( $F_{1} B t$ and $F_{1}$ ISOL); and 84 for each $\mathrm{F}_{2}$ generation $\left(\mathrm{F}_{2} \mathrm{Bt}\right.$ and $\mathrm{F}_{2}$ ISOL).

Three seeds of the same genotype were sown per plot, and after 20 days serological strip tests were performed and results were used to the choice of the seedling to be maintained in the field. Considering the cross DP 404 BG vs. MT 0541, all the $F_{1}$ plants expressed the Cry1Ac protein, and among the $F_{2}$ plants, only one expressed the CrylAc protein and was maintained, the rest were discarded. Transgene expression was qualitatively detected using SeedChek Bt1Ac Test Strips (Strategic Diagnostics Inc., USA). The test was used on 17 DP404 BG individuals, $37 \mathrm{~F}_{1}$ individuals (DP $404 \mathrm{BG}$ vs. MT 0541) and on $170 \mathrm{~F}_{2}$ individuals (DP 404 BG vs. MT 0541). The plants of isoline DP 4049 were considered negative controls. For the strip test a sample of fresh foliar tissue was collected from each plant-leaf disks of about $10 \mathrm{~mm}$

Table 1 The crosses and resultant genotypes designation.

\begin{tabular}{lllll}
\hline & $\mathrm{DP}$ 404 BG & $\mathrm{DP}$ 4049 & $\mathrm{F}_{1} \mathrm{Bt}$ & $\mathrm{F}_{1}$ ISOL \\
\hline MT 0541 & $\mathrm{F}_{1} \mathrm{Bt}$ & $\mathrm{F}_{1}$ ISOL & & \\
$\mathrm{F}_{1} \mathrm{Bt}$ & & & $\mathrm{F}_{2} \mathrm{Bt}$ & \\
$\mathrm{F}_{1}$ ISOL & & & & $\mathrm{F}_{2}$ ISOL \\
\hline
\end{tabular}


of diameter, cut with $1.5 \mathrm{~mL}$ microtubes caps. The samples were then ground with pestles and the test carried out according to the manufacturer's protocol.

The following characters were evaluated: (1) days to germination: number of days from planting to the emergence of seedlings; (2) germination rate, proportion of seedlings emerged by the 15 th day after the planting; (3) days to flowering: number of days from planting to the opening of the first flower; (4) days to the appearance of the first boll: number of days from planting to the opening of the first boll; (5) height at maturation: height, in centimeters, of plants at the end of the cycle, 160 days after the planting; (6) number of bolls per plant: all bolls were collected in individual bags and counted; (7) number of seeds per boll: estimated as a sample taken from three bolls in the lower, middle and upper third; (8) number of seeds per plant: total number of seeds produced by each plant, estimated by multiplying the number of bolls and the number of seeds per boll.

No caterpillar control was used. However, beta-cyfluthrin $80 \mathrm{~mL} \cdot \mathrm{ha}^{-1}$ (Bulldock $125 \mathrm{SC}$ ) was applied once, to control an outbreak of boll weevil (Anthonomus grandis), at the beginning of flower bud formation. Pink bollworm (Pectinophora gossypiella) and cotton leaf worm (Alabama argillacea) occurred naturally. The damage caused by the pink bollworm was estimated based on the proportion of attacked bolls. From each plant, 30 bolls were randomly sampled, 10 from each third of the plant (upper, middle or above parts), at the time of harvest. The bolls that had pink bollworms inside or exhibited signs of damage caused by the pest were considered attacked.

The evaluation of the defoliation caused by cotton leaf worms was done during the period of the plague flight, in February 2008. A scale of grades that ranged from 1 to 5 was used. Grade 1 was attributed to the individuals that presented leaves without significant damage, while grade 5 was attributed to those leaves with severe damage, where leaf was almost completely destroyed. Intermediary damage was graded between 1 and 5 with typical leaf damage per grade indicated in Fig. 1.

\section{Results and Analysis}

The expression of Cry1Ac was dominant and segregated in a proportion of $3: 1$ in the $F_{2}$ population.

The analysis of Cry1Ac gene expression using the kit SeedChek Bt1Ac Test Strips (Strategic Diagnostics Inc. USA) showed that all individuals of DP 404 BG genotype and from the $\mathrm{F}_{1}$ generation (DP $404 \mathrm{BG}$ vs. MT 0541) expressed the Cry1Ac protein. In the $F_{2}$ generation, 122 plants expressed the protein while 48 did not.

The proportion of bolls affected by pink bollworms, which hit approximately 55 days after planting, was less in plants carrying the Bt gene, as shown in Table 2. It ranged from $1.2 \%\left(\mathrm{~F}_{1} \mathrm{Bt}\right)$ and $3.5 \%\left(\mathrm{~F}_{2} \mathrm{Bt}\right)$ to $22 \%$ (MT 0541) and 24\% (DP 4049), respectively. The differences among the genetically modified and conventional plants were confirmed using the Median

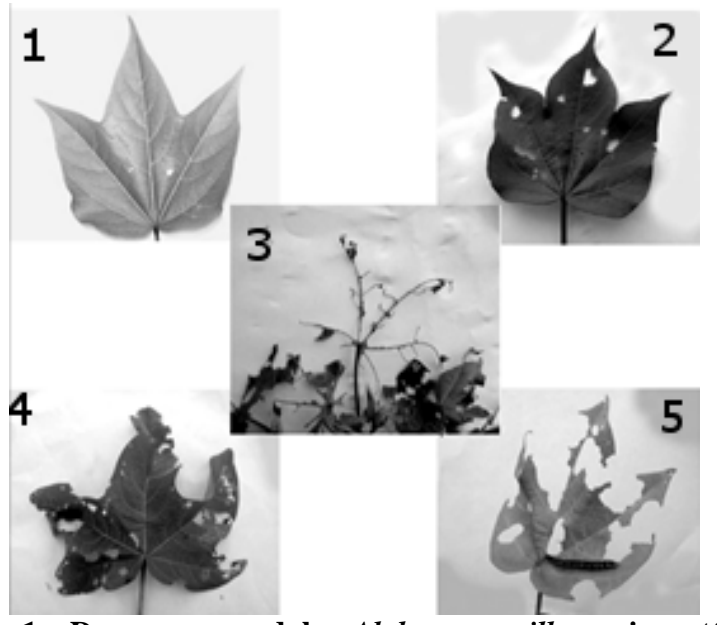

Fig. 1 Damage caused by Alabama argillacea in cotton plants and scale of evaluation. Scores were attributed from 1 to 5 , as shown by the numbers inside the squares.

Table 2 Proportion of bolls attached by pink bollworm. The values above the columns refer to the percent of attacked bolls.

\begin{tabular}{lllllll}
\hline DP & DP & MT & $\mathrm{F}_{1}$ & $\mathrm{~F}_{1}$ & $\mathrm{~F}_{2}$ & $\mathrm{~F}_{2}$ \\
$404 \mathrm{BG}$ & 4049 & 0541 & $\mathrm{Bt}$ & ISOL & $\mathrm{Bt}$ & ISOL \\
\hline $1.8^{\mathrm{a}}$ & $24.5^{\mathrm{b}}$ & $22.6^{\mathrm{b}}$ & $1.2^{\mathrm{a}}$ & $24.3^{\mathrm{b}}$ & $3.5^{\mathrm{a}}$ & $23.5^{\mathrm{b}}$ \\
\hline
\end{tabular}

Values according to Median test $(P<0.01)$. The letters indicate distinct values. 
test $(P<0.01)$, which separated the populations into two groups: the first, containing all plants that expressed the transgenic protein; and the second, formed by the conventional plants. Bolls collected from genetically modified plants qualitatively exhibited less damage that the non-modified plants.

The cotton leaf worm exhibited strong incidence about 130 days after planting, as shown in Fig. 2, and plants could be evaluated according to defoliation degree, with values varying from one (non-existent, inexpressive damage) to five, as shown in Fig. 1. The DP 404 BG genotypes were always scored as grade one (Fig. 1) and non-transgenic G. hirsutum plants were strongly defoliated, while $\mathrm{F}_{2}$ populations showed intermediary defoliation. There was less defoliation caused by cotton leaf worm in genetically modified plants than in conventional plants, according to Median test $(P<0.01)$.

The number of days to germination did not differ significantly among genotypes, as shown in Table 3. The genotype MT 0541 germinated earliest indicating that for this genotype dormancy was not present,
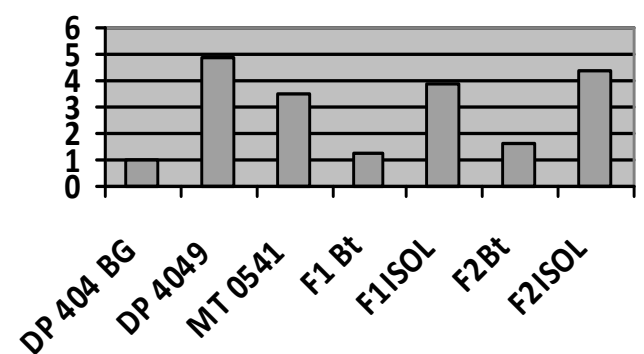

Fig. 2 Level of damage caused by Alabama argillacea in cotton, according to the scale proposed from 1 to 5. while for the others in particular the $G$. barbadense accessions collected in Brazil water absorbance was slow, possibly due to a hard seed coat, delaying germination.

Flowering occurred earlier in herbaceous cotton plants, DP 404 BG (53 days), DP 4049 (58 days), and the hybrids $F_{1}$ (53 to 54 days), than in $F_{2}$ populations (on average 59 or 60 days). All populations presented a number of days to flowering significantly lower than the G. barbadense that flowered about the 113th day, as shown in Table 3. As the rainy period in the semi-arid areas is short and irregular, the more adapted individuals are those that flower or open their bolls prematurely.

The populations behaved similarly with regards the number of days to opening of the first boll, as seen in Table 3. Herbaceous individuals (G. hirsutum) were more premature, followed by the hybrid populations $\mathrm{F}_{1}$, and $\mathrm{F}_{2}$. G. barbadense plants flowered later and the opening of the first boll was also later. The number of days to flowering and formation of the first boll were not significantly different in $\mathrm{F}_{1}$ when compared to $G$. hirsutum plants, suggesting a dominant effect of these traits.

The tallest plants at maturation were G. barbadense (around $2.2 \mathrm{~m}$ high). The $\mathrm{F}_{1}$ populations were significantly shorter $(1.6 \mathrm{~m}$ and $1.5 \mathrm{~m})$, and did not differ from the average height of $F_{2}$ populations (1.3 $\mathrm{m}$ and $1.4 \mathrm{~m})$. The herbaceous cotton plants were the shortest: the DP 404 BG with $1.0 \mathrm{~m}$ and the DP 4049 with $0.7 \mathrm{~m}$. Even though shorter heights are considered

Table 3 Days to germination (DG); germination rate (GR, in percentage); days to flowering (DF); days to the opening of the first boll (DB); height at maturation (HM, in centimeters); bolls per plant (BP); number of seeds per boll (SB); number of seeds per plant (SP).

\begin{tabular}{lllllcccc}
\hline & DG & GR & DF & DB & HM & BP & SB & SP \\
\hline DP 404 BG & 5.45 & $2.35 \mathrm{ab}$ & $52.50 \mathrm{a}$ & $100.85 \mathrm{a}$ & $104.9 \mathrm{~cd}$ & $71.55 \mathrm{bc}$ & $33.4 \mathrm{a}$ & $2384.7 \mathrm{ab}$ \\
DP 4049 & 5.60 & $2.30 \mathrm{ab}$ & $57.60 \mathrm{ab}$ & $96.85 \mathrm{a}$ & $77.90 \mathrm{~d}$ & $57.10 \mathrm{~cd}$ & $30.0 \mathrm{a}$ & $1663.1 \mathrm{bc}$ \\
MT 0541 & 5.50 & $2.75 \mathrm{a}$ & $113.45 \mathrm{c}$ & $158.65 \mathrm{~d}$ & $218.90 \mathrm{a}$ & $18.95 \mathrm{~d}$ & $7.9 \mathrm{~d}$ & $147.4 \mathrm{~d}$ \\
$\mathrm{~F}_{1}$ Bt & 6.29 & $2.29 \mathrm{ab}$ & $53.65 \mathrm{a}$ & $102.06 \mathrm{ab}$ & $155.59 \mathrm{~b}$ & $137.74 \mathrm{a}$ & $21.7 \mathrm{~b}$ & $3018.2 \mathrm{a}$ \\
$\mathrm{F}_{1}$ ISOL & 6.26 & $2.53 \mathrm{ab}$ & $52.97 \mathrm{a}$ & $100.41 \mathrm{ab}$ & $151.32 \mathrm{~b}$ & $97.79 \mathrm{ab}$ & $21.1 \mathrm{~b}$ & $2074.6 \mathrm{ab}$ \\
$\mathrm{F}_{2}$ Bt & 6.15 & $2.23 \mathrm{ab}$ & $59.48 \mathrm{~b}$ & $108.63 \mathrm{c}$ & $126.93 \mathrm{bc}$ & $91.10 \mathrm{~b}$ & $16.0 \mathrm{c}$ & $1451.9 \mathrm{c}$ \\
$\mathrm{F}_{2}$ ISOL & 5.95 & $2.02 \mathrm{~b}$ & $59.96 \mathrm{~b}$ & $104.82 \mathrm{bc}$ & $141.43 \mathrm{bc}$ & $72.70 \mathrm{bc}$ & $14.8 \mathrm{c}$ & $1111.9 \mathrm{c}$ \\
\hline
\end{tabular}

Different letters indicate distinct values according to Median test $(P<0.05)$. 
advantageous for cultivation, mainly to facilitate the harvest, $G$. barbadense continues to be maintained on dooryards [4]. This suggests that height is an important character that not only distinguishes $G$. barbadense species, but is potentially attributed to medicinal properties and can be considered an adaptive advantage.

The quantity of bolls produced by an individual is an important production descriptor and higher numbers indicate adaptability. The $F_{1}$ hybrids produced more bolls (an average of 98 and 138 in Table 1) than the herbaceous parents ( 72 or 58 bolls per plant) and the G. barbadense parents (19 bolls per plant). The average boll per plant in the $\mathrm{F}_{2}$ population was slightly lower than the $F_{1}$ but higher than the parents.

The number of seeds per bolls was highest in herbaceous cotton plants and least in MT 0541. Both $F_{2}$ populations were similar and produced less seeds per boll than $F_{1}$. The number of seeds per plant is an important production descriptor in cotton for which, higher values increase adaptability.

Corky genotypes, which can be found in around 1.2 to 4.6 of $F_{2}$ plants derived from outcrossing between G. mustelinum and G. barbadense [12], did not occur in this population.

\section{Discussion}

The hybrids resultant from the crossing $G$. barbadense with $G$. hirsutum presented greater fitness than their parents when measured by an increase in reproductive capacity and the number of seeds per plant, as shown for wild radish in California [3]. Considering natural selection alone, this could favor maintenance of the hybrids and even displacement of the parents. But $G$. barbadense is known not to occur in natural environments in Brazil as several expeditions to various states including Mato Grosso [5], Pará, Amapá [4], Pernambuco, Acre, Roraima, Amazonas, Tocantins, Distrito Federal, Mato Grosso do Sul, Maranhão, Piauí, Ceará, Paraíba, Pernambuco,
Alagoas, Sergipe, Bahia, Minas Gerais, Rio de Janeiro, São Paulo, Santa Catarina, Rio Grande do Sul [13] confirm that the plants were always found in dooryards. Therefore, the main selection mechanism is the artificial selection, which may be driven by the belief of properties attributed to the species, mainly as a medicinal plant. The yield reached depends on the environmental conditions. Plants were distant to each other, resembling the way they are found in dooryards. Competition among plants was not favored as in a crop field.

Non transgenic G. barbadense genotypes were slightly more resistant to both worm species than non-transgenic G. hirsutum, and further studies with other genotypes of the species may show its value as a genetic source of resistance. This difference may be attributed to differential concentrations of phenolic acids in the individual plant species as phenolic acids are considered to be important factors in natural resistance to insects [14].

When the trait of insect resistance is excluded, in the absence of worms, no observable differences using both vegetative and reproductive parameters were found between transgenic and non-transgenic plants. The comparisons were done on both the $F_{1}$ and $F_{2}$ populations with and without the transgene and neither $\mathrm{F}_{1} \mathrm{Bt}$ and the isoline nor $\mathrm{F}_{2} \mathrm{Bt}$ and the isoline differed in the vegetative (days to germination, germination rate, days to flowering, days to the opening of the first boll, height at maturation); or reproductive (bolls per plant, number of seeds per boll, number of seeds per plant) traits analyzed. Thus, introgression of the transgene is not expected to cause a significant impact on the adaptability of $F_{1}$ and $F_{2}$ generations derived from interspecific crossings. All the $F_{2}$ Bt plants of the evaluated population were selected to express the transgene using the SeedChek Bt1Ac Test Strips. For the MT 0541 which is a perennial genotype the first year is focused on vegetative growth and in subsequent years an increase in seeds and bolls production is observed as in relative 
adaptability.

The pink bollworm is the main pest found in $G$. barbadense plants maintained in Brazil in situ [5, 13]. The resistance to pink bollworm is greater in the plants carrying the $\mathrm{Bt}$ gene and thus the number of viable seeds generated by Bt plants is expected to be greater than that of the non-transgenic plants, and likewise the fitness.

Alabama argilacea infestation occurred after the plants had produced bolls particularly when the bolls were open. This was followed by some rain that enabled an onset of new leaves which were exposed to A. argillacea. The plants bearing $\mathrm{Bt}$ gene were markedly more resistant to defoliation by $A$. argillacea, suggesting that if the infestation occurred prior to seed production, it could have decreased seed production in non Bt plants. Transgenic Bt plants were slightly damaged by Alabama argilaceae, similarly as described by Wan et al. [15].

The expression of genetic traits varies with the environment [16], and the efficacy of Bt cotton depends on the level of expression of the gene and protein synthesis [17]. Plants were resistant to the worm in spite of high temperatures. It has been reported that temperatures over $37{ }^{\circ} \mathrm{C}$ may diminish the resistance conferred by the Bt gene [18]. Furthermore, the infections occurred during late development, when resistance conferred by $B t$ genes may diminish [19].

The presence of individuals that are superior to both parents may be frequent among the $F_{2}$ populations. The adaptability of a population may be measured by the median values that characterize it, but evolution depends on the success of particular individuals. The crossing with $G$. hirsutum influences the fitness with an increase in the reproductive capacity as measured by the number of seeds per plant. The general adaptability is influenced also by the introgression of $\mathrm{Bt}$ and consequent resistance to worms. Both the traits are dominant, but the $\mathrm{Bt}$ gene as a monogenic trait is easier to introgress than seed production.
Fitness aims to predict plant population behavior [20]. Artificial and natural selection must be differentiated when considering the consequences of crosses with $G$. hirsutum for in situ maintenance of $G$. barbadense in Brazil. The in situ maintenance of $G$. barbadense in dooryards is not so much influenced by the number of seeds per plant but rather beliefs linked medicinal values of the plant. Fitness is decisively related to natural maintenance, but may be not essential for artificial selection.

Both the genetic characteristics of traditional cultivars of $G$. hirsutum as well as the transgene may increase the natural or artificial selection of $G$. barbadense by favoring the selection of superior hybrids in place of pure G. barbadense parents. The isolation from traditional cotton cultivars is more important than the isolation from the transgene. One means to prevent crossing is to take advantage of the reproductive isolation of the traditional cultivars from the transgene. However, reproductive isolation should not be the only conservation measure, and measures to preserve pure genotypes both in situ and ex situ should be considered.

\section{Conclusions}

The hybrids of first and second filial generations resultant from the crossing Gossypium barbadense with G. hirsutum show a greater reproductive capacity than their parents. Transgenic hybrids bearing Cry1Ac perform better when plants are exposed to Alabama argillacea or Pectinophora gossypiella pests, thus the Cry1Ac transgene is postulated to confer indirect fitness or adaptation when pests are considered.

The preservation of pure G. barbadense can be improved by reproductive isolation, and preventing crossings with traditional upland cotton cultivars is more important than the isolation from the transgene. However, reproductive isolation is not enough, since the use of medicinal plants have progressively diminished. 


\section{Acknowledgments}

Thanks to Embrapa and CNPq for financial support, José Henrique de Assunção for field assistance.

\section{References}

[1] N.C. Ellstrand, H.C. Prentice, J.F Hancock, Gene flow and introgression from domesticated plants into their wild relatives, Annual Review of Ecology and Systematics 30 (1999) 539-563.

[2] A.C.A. Dantas, P.A.V. Barroso, L.V. Hoffmann, M.F. Alves, F.P. Andrade, SSR markers to detect gene flow from upland to mocó cotton, Ciência Agronômica 43 (2012) 163-169.

[3] S.G. Hedge, J.D, Nason, J.M. Clegg, N.C. Ellstrand, The evolution of California wild radish has resulted in the extinction of its progenitors, Evolution 60 (6) (2006) 1187-1197.

[4] R. Guadagnuolo, J. Clegg, Ellstrand, Relative fitness of transgenic vs. non-transgenic maize $\times$ teosinte hybrids: A field evaluation, Journal of Applied Ecology 16 (5) (2006) 1967-1974.

[5] V.C. Almeida, L.V. Hoffmann, G.K.I. Yokomizo, J.N. Costa, M. Giband, P.A.V. Barroso, In situ and genetic characterization of Gossypium barbadense populations from the states of Pará and Amapá Brazil, Pesquisa Agropecuária Brasileira 44 (7) (2009) 719-725.

[6] P.A.V. Barroso, J.N. Costa, A.Y. Ciampi, L.P. Rangel, L.V. Hoffmann, In situ characterization of Gossypium barbadense populations from the state of Mato Grosso, Embrapa-CNPA, Technical report number 244, Campina Grande, 2005. (in Portuguese)

[7] I.P.P. Menezes, P.A.V. Barroso, L.V. Hoffmann, V.S. Lucena, M. Giband, Genetic diversity of mocó cotton (Gossypium hirsutum race marie-galante) from the northeast of Brazil: Implications for conservation, Botany 88 (2010) 765-773.

[8] G.S. Pereira, R.L. Sousa, R.L. Araújo, L.V. Hoffmann, E.F. Silva, P.A.V. Barroso, Selective fertilization in interspecific crosses of allotetraploid species of Gossypium, Botany 90 (2012) 159-166.

[9] O. Shilla, T.P. Hauser, F.I. Tibazarwa, Cross compatibility of cultivars of Gossypium hirsutum and feral Gossypium barbadense from the Southern Highlands of Tanzania, African Journal of Crop Science. (accepted)
[10] P.E. Arriola, N.C. Ellstrand, Fitness of interspecific hybrids in the genus Sorghum: Persistence of crop genes in wild populations, Ecological Applications 7 (1997) 521-528.

[11] E.R. Sujii, P.H.B. Togni, Y.E.T. Nakasu, C.S.S. Pires, D.P. Paula, E.M.G. Fontes, Impact of Bt cotton on the population dynamics of the cotton aphid in greenhouse, Pesquisa Agropecuária Brasileira 43 (10) (2008) 1251-1256. (in Portuguese)

[12] E.C. Freire, Viability of crossing between transgenic, commercial and wild species of cotton in Brazil, Revista Brasileira de Oleaginosas e Fibrosas 6 (1) (2002) 465-470. (in Portuguese)

[13] Albrana, Brazilian Native and Naturalized Cotton, 2014, http//www.cnpa.embrapa.br/albrana.

[14] G. Magarelli, J.G. Silva, I.A. Sousa Filho, I.S.D. Lopes, J.R. Souza, L.V. Hoffmann, et al., Development and validation of a voltammetric method for determination of total phenolic acids in cotton cultivars, Microchemichal Journal 102 (2012) 1-6.

[15] P. Wan, K. Wu, M. Huang, J. Wu, Seasonal pattern of infestation by pink bollworm Pectinophora gossypiella (Saunders) in field plots of Bt transgenic cotton in the Yangtze River valley of China, Crop Protection 23 (2004) 463-467.

[16] V.A. Pontes Júnior, L.C. Melo, H.S. Pereira, M.J. Del Peloso, L.C. Faria, A. Wendland, et al., Productive potential and interaction of elite bean lines with environments in the Central Cerrado of Brazil, Crop Breeding and Applied Biotechnology 12 (2012) 8-16.

[17] A.P. Gutierrez, J.J. Adamczyk, S. Ponsard, C. K. Ellis, Physiologically based demographics of Bt cotton-pest interactions II. Temporal refuges, natural enemy interactions, Ecological Modeling 191 (2006) 360-382.

[18] D. Chen, G. Ye, C. Yang, Y. Chen, Y. Wu, The effect of high temperature on the insecticidal properties of $\mathrm{Bt}$ cotton, Environmental and Experimental Botany 53 (2005) 333-340.

[19] J.J. Adamczyc, D.V. Sumerford, Potential factors impacting season-long expression of Cry1Ac in 13 commercial varieties of Bollgard cotton, Journal of Insect Science 1 (2001) 1-6.

[20] E. Sober, The two faces of fitness, in: R. Singh, D. Paul, C. Krimbas, J. Beatty, (Eds.), Thinking about Evolution: Historical, Philosophical, and Political Perspectives, University Press of Cambridge, Cambridge, 2001, pp. 309-321 (Chapter 15). 